\title{
Erratum to: Heterogeneous Catalytic Hydrogenation of Ethyl Acetate to Produce Ethanol
}

\author{
Mingsheng Luo • Tapan K. Das • Constantin Delibas •
}

Burtron H. Davis

Published online: 20 February 2014

(C) Springer Science+Business Media New York 2014

\section{Erratum to: Top Catal}

DOI 10.1007/s11244-013-0232-x

For this article, the first author should be: Mingsheng Luo.

The correct author list appears in this erratum.

The online version of the original article can be found under doi:10.1007/s11244-013-0232-x.

M. Luo · T. K. Das · B. H. Davis $(\bowtie)$

Center for Applied Energy Research, University of Kentucky,

2540 Research Park Drive, Lexington, KY 40511, USA

e-mail: Burtron.davis@uky.edu

C. Delibas

Woodland Biofuels, Inc., 220 Superior Blvd., Mississauga,

ON L5T 2L2, Canada 